\title{
VYGOTSKY E O ENSINO E APRENDIZAGEM DE LÍNGUAS
}

FIGUEIREDO, Francisco José Quaresma de. Vygotsky: A Interação no Ensino/Aprendizagem de Línguas. São Paulo: Parábola, 2019.

Rosa Yokota*

O livro Vygotsky: A Interação no Ensino/Aprendizagem de Linguas' ${ }^{1}$ é fruto do estágio pós-doutoral do professor da Universidade Federal de Goiás (UFG), Francisco José Quaresma de Figueiredo, realizado na Universidade Federal de Minas Gerais (UFMG) sob a supervisão de Laura Stella Miccoli, que escreveu o prefácio do livro. É uma leitura que atenderá públicos com diferentes níveis de familiaridade com a teoria: estudantes em formação, profissionais da área educação e, principalmente, aqueles que se dedicam à psicolinguística e à linguística aplicada ao ensino e à aprendizagem de línguas.

No Brasil, a obra de Vygotsky foi introduzida nos anos 80 em universidades paulistas, quando passou a ser objeto de estudo de pesquisadores da área de educação da PUC/SP e da Unicamp, como explicam Mainardes e Pino (2000) em artigo que apresenta um levantamento das publicações sobre o autor no Brasil. Também são dos anos 80 as primeiras

\footnotetext{
* Doutora em Letras (Língua Espanhola e Literatura Espanhola e Hispano-Americana) pela Universidade de São Paulo (Usp). Professora associada da Universidade Federal de São Carlos (UFSCar). 
traduções, pela Editora Martins Fontes, da obra de Vygotsky. Além da tradução ao português, Figueiredo consultou uma das principais traduções da obra de Vygotsky do russo ao espanhol, cuja edição é cubana, e textos traduzidos ao inglês em sua pesquisa.

Apesar de não ser uma obra introdutória ou para leigos, o livro aclara, interpreta e ilustra através de figuras esquemáticas uma série de conceitos que são essenciais para entender e desenvolver os estudos e práticas a partir da teoria sociocultural.

No primeiro capítulo, "Vygotsky e sua teoria", são trazidas informações sobre sua vida, em especial sua formação acadêmica em várias áreas (história, filosofia, psicologia, literatura, direito e até medicina). $\mathrm{O}$ autor apresenta uma ideia de quais eram as abordagens da psicologia naquele então: teoria behaviorista e a Gestalt e mostra a insuficiência delas para as inquietações de Vygotsky. Assinala, também, a importância das ideias de Marx e Engels para o método genético (desenvolvimental) de Vygotsky, que enfatiza o papel da história e das relações sociais no desenvolvimento mental e comportamental do indivíduo. Assim, expõe-se brevemente que o comportamento do ser humano não é só um produto de evolução biológica, mas também é produto do desenvolvimento histórico-cultural da comunidade. Além de apresentar o contexto de surgimento da teoria, há também, no primeiro capítulo, a interpretação dada por alguns autores à teoria sociocultural.

No capítulo 2, "As falas egocêntrica, interior e privada”, Figueiredo faz referência a Piaget (1993) para explicitar a interpretação dada por Vygotsky à fala não socializada da criança, estudada por Piaget (1993) em A linguagem e o pensamento da criança. Em Pensamento e Linguagem, Vygotsky (1993) defende que a fala da criança é essencialmente social e dividese em comunicativa (a criança fala para interagir com outras pessoas) e egocêntrica (que se converte em fala interior ou privada, a criança fala consigo). Apesar da importância dada ao diálogo social (interpessoal) no desenvolvimento cognitivo da criança, o lugar da fala egocêntrica nos estudos sobre a teoria sociocultural de Vygotsky é destacado por Figueiredo. O autor retoma os três estágios do desenvolvimento cognitivo segundo Vygotsky para explicar que a fala não tem a função somente de comunicação, mas atende também 
os propósitos de planejar, guiar e monitorar o próprio comportamento de forma autorregulada por meio da fala privada ou interior. Ou seja, a fala tem uma função intrapessoal, quando a criança, ao falar consigo mesma, provê a si mesma auxílio cognitivo por meio de enunciados linguísticos.

Diferentemente de Piaget, Vygotsky não aceita a ideia de que a linguagem egocêntrica desaparece com o desenvolvimento da criança, ele defende que ela se transforma em fala interior. Figueiredo seleciona uma série de estudos e pesquisas e analisa o desenvolvimento cognitivo apresentado pelos participantes focalizando a fala egocêntrica, a fala interior e a fala privada na infância (LM) ou na idade adulta (LM, LE ou L2). O fato de referirse a adultos diferencia a obra de Figueiredo de outros textos, afinal, ele reúne em seus exemplos situações de aquisição, aprendizagem e ensino de LE ou L2. Entre os estudos comentados, temos situações em Libras, demonstrando a amplitude da pesquisa de Figueiredo e sua preocupação com a educação inclusiva.

No terceiro capítulo, “A mediação e a ZDP”, inicialmente, Figueiredo retoma o conceito de mediação, tão importante na teoria vygotskyana. Segundo ele:

A mediação é a intervenção de um elemento intermediário em uma relação que o homem tem com os objetos, com outros seres humanos e consigo mesmo, e esse elemento mediador pode ser um instrumento (ou ferramenta), um signo ou outros seres humanos. (FIGUEIREDO, 2019, p.37)

A explicação de que é instrumento na teoria sociocultural é apresentada nas páginas seguintes, destacando que os instrumentos são social e culturalmente construídos e tem efeito sobre a mente e sobre o contexto dos que os utilizam. Entre os instrumentos psicológicos socialmente construídos, destaca-se a linguagem. Por meio da fala, os seres humanos podem ser mediadores para seus pares. Esse tipo de mediação (pela língua ou por outros sistemas simbólicos) é conhecido como mediação semiótica. Figueiredo traz exemplos de mediação e de estratégias de mediação no processo de aprendizagem de LE/L2, em que se destacam as ferramentas tecnológicas. 
Também é apresentada a interpretação dada para mediação metacognitiva e cognitiva por Karpov \& Haywood (1998 apud FIGUEIREDO, 2019, p. 40-41). A mediação metacognitiva está relacionada com a autorregulação pela criança por meio da interação com outras pessoas. A autorregulação, segundo o autor, deriva de um processo de internalização de operações que ocorrem em interações no meio social. A mediação cognitiva está relacionada com conceitos cotidianos (experiências do dia a dia) e conceitos científicos (relacionados com o ambiente escolar). Ou seja, as interações na vida cotidiana e no ambiente escolar levam ao desenvolvimento cognitivo e emocional da criança, entretanto, a teoria vygotskyana chama a atenção para a necessidade das interações assimétricas, ou seja, entre a criança e alguém mais experiente (adulto ou outra criança) para que a criança possa desenvolver as funções psicológicas superiores (atenção deliberada, lembrança voluntária, memória lógica, pensamento verbal e conceitual, raciocínio dedutivo, etc). As interações mediadas são importantes para entender o conceito de Zona de Desenvolvimento Proximal (ZDP)

Vygotsky (1998) distingue dois níveis de desenvolvimento da criança: o real (o desenvolvimento mental medido retrospectivamente, o que a criança é capaz de fazer sozinha) e o potencial (o que a criança é capaz de fazer com o auxílio de alguém mais experiente). O ZDP é definido como:

[...] a distância entre o nível de desenvolvimento real, que se costuma determinar através da solução independente de problemas, e o nível de desenvolvimento potencial, determinado através da solução de problemas sob a orientação de um adulto ou em colaboração com companheiros mais capazes. (VYGOTSKY, 1998, 112)

A partir da definição anterior, Figueiredo passa a reunir uma série de reflexões sobre a ZDP de diferentes pesquisadores que se debruçaram sobre a obra de Vygotsky e finaliza o capítulo enfatizando que se houver a interação em um grupo para a resolução de um problema, isso proporcionará um processo dialógico em que haverá uma construção colaborativa. 
O quarto capítulo da obra, "A metáfora do scaffolding”, está relacionado à ZDP tratada no capítulo anterior. A metáfora ${ }^{2}$ foi cunhada por Wood, Bruner \& Ross (1976 apud FIGUEIREDO, 2019, p.51) e se refere ao apoio dado por um adulto a uma criança durante tarefas que levam a resolução de problemas, ou seja, trata-se de um conceito que foi associado à teoria sociocultural de Vygotsky e que não é originalmente do autor russo. Este apoio seria temporário, se autodestrói à medida que a criança supera determinada etapa e é substituída por nova estrutura para que suba a um patamar superior.

A importância da instrução e da atuação do professor (do par mais competente ou do tutor) é enfatizada no conceito de scaffolding. Segundo Figueiredo, a expansão da ZDP é favorecida pelo diálogo e pelos scaffoldings dados ao indivíduo por meio da participação guiada em atividades colaborativas. Com a evolução do aprendiz, há também um aumento da autorregulação e da independência, ou seja, há aumento do potencial do aprendiz de realizar algo sozinho e diminuição do que ele não conseguia fazer, a ZDP encolhe e o nível de desenvolvimento potencial passa a ser real. Figueiredo escolhe alguns estudos que abordaram a função do tutor em contextos de ensino aprendizagem de línguas para ilustrar o capítulo e, para finalizá-lo, ele reúne críticas ao uso de scaffolding apresentados por outros autores, como a privação do uso da criatividade pelo aprendiz ou o desvio do objetivo de favorecer a aprendizagem (desenvolvimento cognitivo) em detrimento do resultado (execução de tarefa).

O capítulo "Teoria Sociocultural e aprendizagem de L2/LE" retoma os conceitos apresentados nos capítulos anteriores e passa a mostrar que estão presentes nos estudos e nas práticas da área de ensino-aprendizagem de LE. Assim, o quinto capítulo do livro apresenta reflexões sobre a abordagem baseada em tarefas, a aprendizagem colaborativa de línguas, o uso de jogos em sala de aula, a avaliação dinâmica e a telecolaboração. Ou seja, trata-se de um capítulo de grande interesse para os professores de LE, porém, exige-lhes conhecimentos prévios sobre os temas abordados. 
Além de trazer uma bibliografia que reúne autores introdutores de determinadas vertentes, como Candlin \& Murphy (1987) sobre tarefas; Swain (vários textos) sobre a aprendizagem colaborativa e a lingualização e o próprio Vygotsky sobre a questão dos jogos; Figueiredo nos apresenta também estudos e pesquisas desenvolvidos nos últimos anos com exemplos bastante ilustrativos sobre situações de interação em processos de aprendizagem de inglês, de Libras e de português. Trata-se de um capítulo em que o autor toca também em um tema pouco abordado, como o da avaliação dinâmica, que, pelo fato de demandar tempo e dedicação especial do professor (um tipo de avaliação recomendada para aprendizes que têm dificuldades de aprendizagem, especialmente em contexto de educação especial), é de difícil aplicação no cotidiano da educação escolar básica. Contextos de tandem e teletandem também são tratados pelo autor neste capítulo e ilustrados com exemplos brasileiros. Os exemplos aparecem na língua original e traduzidos, um detalhe que facilita a leitura, e são apresentados exemplos traduzidos da Libras também.

O sexto capítulo, 'A teoria sociocultural na formação de professores', finaliza os temas tratados no livro de forma bastante interessante: trata-se de um capítulo que procurar mostrar como foi a aplicação da teoria para a formação de professores, visto que Vygotsky não se dedicou aos estudos de formação de professores, mas sim ao desenvolvimento do conhecimento no indivíduo. O autor apresenta uma série de estudos e pesquisas que relacionam a noção de ZDP à formação de professores, em que se destaca a colaboração entre professores e de professores com coordenadores, com professores em formação e formadores para o desenvolvimento profissional de todos os envolvidos, tanto em interações presenciais quanto em telecolaboração.

Nas "Considerações Finais" do livro, Figueiredo sintetiza as ideias principais desenvolvidas no decorrer dos capítulos e relembra que os exemplos expostos demonstram que a teoria sociocultural pode estar presente em diferentes contextos de aprendizagem (um empreendimento colaborativo). Destaca que a teoria sociocultural se aplica em contextos de aprendizagem e de formação de professores de línguas tanto orais quanto de sinais, 
apresenta exemplos de contextos universitários, de tandem e teletandem que permitem entender a teoria através de práticas reais. O autor não deixa de apresentar, brevemente, as críticas feitas a Vygotsky, mas baseado nas referências bibliográficas que reuniu, pode demonstrar a vitalidade da teoria sociocultural na atualidade.

\section{REFERÊNCIAS}

FIGUEIREDO, Francisco José Quaresma de. Vygotsky: A Interação no Ensino/Aprendizagem de Línguas. São Paulo: Parábola, 2019.

MAINARDES, Jefferson; PINO, Angel (2000) Publicações brasileiras na perspectiva vigotskiana. Educação \& Sociedade, Campinas: CEDES/Unicamp, n.71, p.255-269, julho/2000.

PIAGET, Jean. A linguagem e o pensamento da criança. São Paulo: Martins Fontes, 1993.

VYGOTSKY, L Pensamento e linguagem. São Paulo: Martins Fontes, 1993.

Recebido em: 19/04/2020.

Aprovado em: 04/06/2020. 